\title{
Predictive Role of p53 Protein as a Single Marker or Associated with ki67 Antigen in Oral Leukoplakia: A Retrospective Longitudinal Study
}

\author{
Davide B. Gissi, Andrea Gabusi, Dora Servidio, Fabio Cervellati and Lucio Montebugnoli*
}

Department of Biomedical and Neuromotor Sciences, Section of Oral Science, University of Bologna, Italy

\begin{abstract}
Oral leukoplakia (OL) is the most common potentially malignant lesion of the oral cavity. Immunohistochemical analysis of p53 and Ki67 proteins is a simple and inexpensive method widely used in non-dysplastic OLs to reveal lesions predicted to develop oral cancer. The present longitudinal study evaluated the predictive role of p53 and Ki67 proteins alone or in combination in a group of OLs without dysplasia followed for many years. Seventy-seven OL patients referred to our Department between January 2006 and October 2013 underwent histochemical analysis of p53 and Ki67 expression. OLs were considered at high risk in the presence of either high p53 expression ( $>20 \%)$, or low/normal p53 expression associated with high Ki67 expression (Ki67/p53 ratio >3). Seven OLs evolved to OSCC during the follow-up period. Three cases had p53 overexpression, while four had a high Ki67/p53 ratio. Statistical significance was reached when samples with p53 overexpression were combined with samples with high Ki67/p53 ratio (Chi square 5.3; p<0.02). The combined immunohistochemical expression of p53 and Ki67 proteins could be a useful and simple molecular marker for early detection of non-dysplastic OLs at risk of developing oral cancer.
\end{abstract}

Keywords: Ki67 protein, oral leukoplakia, oral squamous cell carcinoma, p53 protein.

\section{INTRODUCTION}

Head and Neck cancer is the sixth leading cancer worldwide, with more than 500,000 cases diagnosed every year. The vast majority of head and neck cancers are oral squamous cell carcinomas (OSCCs) that arise from the epithelial lining of the oral cavity, including the tongue and lips [1].

OSCC is often preceded by recognizable potentially malignant disorders. Oral Leukoplakia (OL) is widely considered the most common potentially malignant lesion of the oral cavity and may affect any site of the cavity [2]. The risk of OL malignant evolution is extremely variable, ranging from 4 to $20 \%[3,4]$.

The diagnosis of OL is both clinical and histological and a biopsy is mandatory to exclude other known diseases. Clinically OL can be divided into a homogeneous type (flat, thin, uniform in color) and a non-homogeneous type that includes white-and-red (erythroleukoplakia), irregularly flat (speckled) or nodular lesions. Verrucous leukoplakia is yet another non-homogeneous type that usually has a uniform white appearance with a distinctive verrucous texture [5]. Proliferative Verrucous Leukoplakia (PVL) is a distinct subtype of Verrucous Leukoplakia [6], characterized by multifocal presentation, resistance to treatment and a high rate of malignant transformation [7, 8].

Histopathologically, a distinction can be made between dysplastic and non-dysplastic OLs. High-risk lesions are generally characterized by epithelial dysplasia although its

*Address correspondence to this author at the Department of Oral Sciences, University of Bologna, Via S. Vitale 5940125 Bologna, Italy;

Tel: 0512088136; Fax: 051225208; E-mail: lucio.montebugnoli@unibo.it absence does not preclude malignant transformation [9]. One way to detect genetic alterations in non-dysplastic OLs is to assess the molecular markers associated with OSCC that predict malignant transformation when found in epithelial precursors [9-11]. Immunohistochemical analysis of p53 proteins is a simple and inexpensive method that has been widely used to reveal OLs predicted to develop OSCC. p53 protein is a product of TP53 tumor suppressor gene, and TP53 gene mutations leading to loss of function are the commonest type of genetic damage found in human cancers and OSCC, often preceding recognizable histological alterations [11-13]. In about $50 \%$ of cases, TP53 mutations determine an overproduction of $\mathrm{p} 53$ inactive proteins resulting in the immunohistochemical overstaining frequently found in OSCC and in lesions predicted to develop OSCC, and considered a good marker to predict malignant transformation of OLs. However, some mutations lead to transcription or translation errors which result in reduced p53 protein synthesis and reduced staining on immunohistochemistry. This may be difficult to interpret as a pathological status, considering the significant inter and intrasubject variability in daily p53 production and the lack of consensus in the cutoff differentiating "normal" from reduced $\mathrm{p} 53$ expression.

In a previous cross-sectional study, we found that "normal" or reduced p53 expression, when combined with high Ki67 protein expression as an immunohistochemical marker of proliferating cells, demonstrated a higher predictive power than when taken alone [14]. The rationale was that normal cells undergoing increased proliferation due to factors such inflammation, trauma, etc. usually accumulate p53 protein that is considered a physiologic response safeguarding epithelial growth. It follows that the finding of high Ki67 values associated with normal or low p53 values (high Ki67/p53 ratio) may suggest an impaired p53 production as a 
consequence of TP53 gene damage. The results of that study showed that samples with high p53 scores considered together with samples with normal p53 but elevated Ki67/p53 (increased mitotic/apoptosis ratio) included $93 \%$ of OSCC and $81 \%$ of OLs with moderate or severe dysplasia.

The aim of the present longitudinal study was to follow a population of patients with an initial diagnosis of OL without signs of dysplasia to determine whether p53 alone or combined with Ki67 could have a predictive power to detect nondysplastic OLs that developed to OSCC.

\section{MATERIAL AND METHODS}

The study cohort comprised 77 OL patients referred to the Department of Biomedical and Neuromotor Sciences, Section of Oral Sciences, University of Bologna, Bologna (Italy) between January 2006 and October 2013. Of the 77 patients, 34 were males and 43 females aged 26-95 years mean $61.6 \pm 13.8$. Eight OLs were on the cheek, five on the tongue, 19 in the gum, three on the hard palate, and one on the lip. Sixty OLs appeared as white homogeneous lesions, while 17 OLs were white or white/red inhomogeneous lesions. All samples underwent histological and immunohistochemical analysis and a minimum follow-up of 12 months was available.

OL was clinically defined as a white patch or plaque that could neither be rubbed off nor diagnosed as any specific disease [15]. Histological diagnoses were performed at Bellaria Hospital, Department of Pathology of the University of Bologna (Bologna, Italy). Hematoxylin-eosin (H\&E) stained sections from all the cases were reviewed by one pathologist with experience in oral pathology (MPF) who was unaware of the clinical outcomes. Histological diagnoses were performed following the criteria described in the World Health Organization's blue book [16]. On histology, all lesions showed squamous cell hyperplasia (simple hyperplasia, according to the Ljubljana classification), characterized by increased basal-parabasal layers and acanthosis in the absence of architectural alterations [17]. Leukoplakias with signs of dysplasia were not included in the study population.

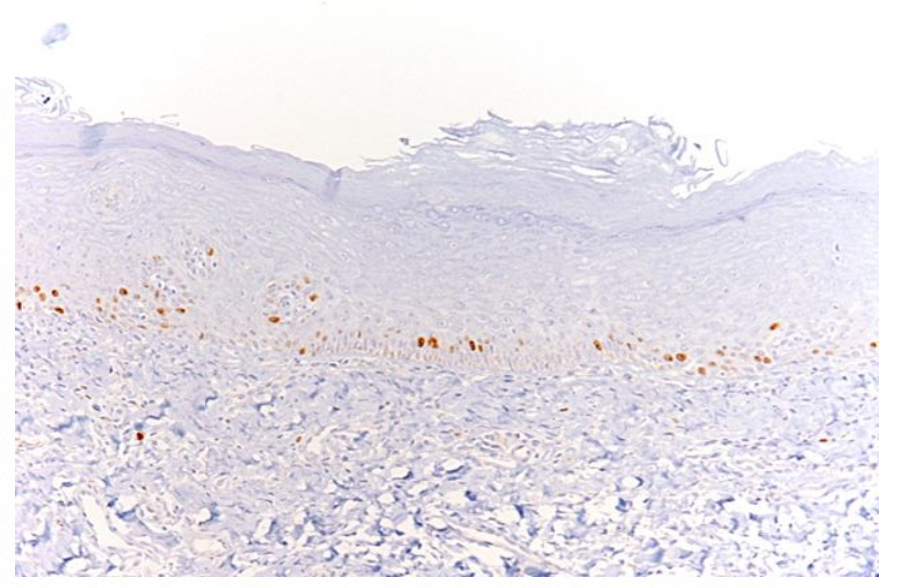

(a)
Immunostaining was performed on $2 \mu \mathrm{m}$ thick sections serially cut from the selected blocks. The following antibodies were employed: monoclonal anti-Ki67 (Dako, Denmark, clone MB-1 diluted 1:200) and monoclonal anti-p53 (Dako, clone p53, diluted 1:50). Processing was performed in an automatic stainer (Autostainer, Ventana, USA). All the cases contained an internal control as basal cells of the oral epithelium show nuclear positivity for the two markers under study. Negative controls consisted in omitting the primary antibody. Counting the percentage of positive nuclei in 400 consecutive epithelial cells of selected areas representative of the lesion gave a semi quantitative evaluation of the immunohistochemical results.

p53 values were considered high (p53 overexpression) equal to or more than $20 \%$; the Ki67/p53 ratio was considered high when equal to or more than 3 [14]. Fig. (1a, 1b) and Fig. (2a, 2b) show examples of low and high immmunohistochemical expression of Ki67 and p53 protein respectively.

\section{STATISTICAL ANALYSIS}

Patients' age, sex, smoking behavior, site, clinical appearance, p53 overexpression, and high Ki67/p53 ratio were analyzed for their relationship with risk of progression to OSCC during follow-up. The Cox proportional hazards method with forward selection was used as multivariate survival analysis. Time was defined as the period between diagnosis and the target event or last follow-up. P values $<.05$ were considered statistically significant in all analyses.

\section{RESULTS}

Table 1 lists the features of the study population. p53 overexpression was found in 19 samples $(24.7 \%)$. A high Ki67/p53 ratio was found in 27 samples (35.1\%).

Seven OLs (10\% of all OLs) evolved to OSCC during follow-up period. Three cases had p53 overexpression at presentation and developed to OSCC after 30, 36 and 60 months respectively, while four cases had high Ki67/p53 ratio and all developed to OSCC within six months. None of the OLs with normal p53 expression and normal Ki67/p53 ratio evolved to OSCC.

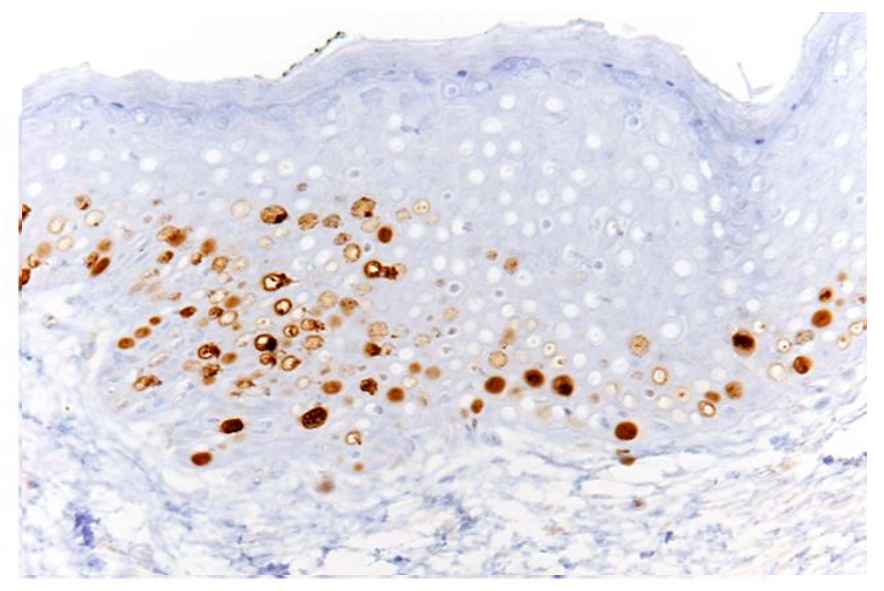

(b)

Fig. (1). Examples of OL with low Ki67 expression limited to basal keratinocytes (a) and OL with Ki67 high expression (b). 


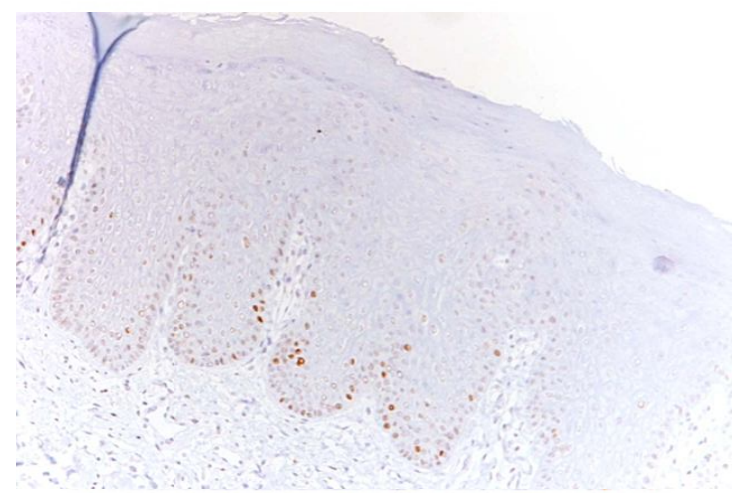

(a)

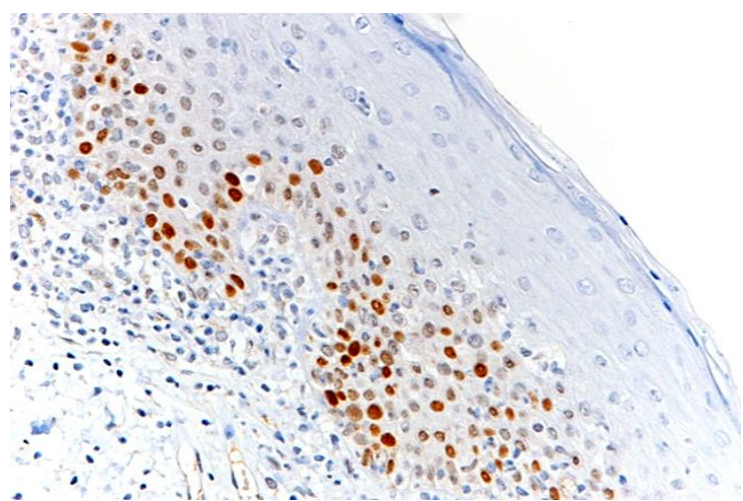

(b)

Fig. (2). Examples of OL with low p53expression (a) and OL with high p53 expression (b).

Table 1. Features of the study population.

\begin{tabular}{|c|c|c|c|}
\hline & $\mathbf{N}^{\circ}$ & $\%$ OLs evolved to OSCC & Significance $\mathbf{p}$ \\
\hline Age $<65 v s>65$ & $48 / 29$ & 6.3 vs 13.3 & 0.30 \\
\hline Smokers $v s$ no smokers & $35 / 42$ & 2.9 vs 4.3 & 0.08 \\
\hline Dysomogeneus $v s$ omogeneus appearance & $17 / 60$ & 17.6 vs 6.7 & 0.20 \\
\hline High $v s$ normal Ki67/p53 ratio & $27 / 50$ & 14.8 vs 6.0 & 0.17 \\
\hline High p53 expression and high Ki67/p53 ratio $v s$ all remaining samples & $36 / 31$ & $19.4 v s 0$ & 0.02 \\
\hline
\end{tabular}

Fig. (3a, 3b) shows a 77-year-old non-smoking female who initially presented a non-homogeneous leukoplakia of the marginal tongue without signs of dysplasia but with high p53 expression (50\%) at immunohistochemical analysis; 36 months later she developed OSCC.

The results of the Cox proportional hazards method showed that the only significance was reached when samples with p53 overexpression were combined with samples with a high Ki67/p53 ratio (Chi square 5.3; p<0.02) (Fig. 4).

\section{DISCUSSION}

The clinician's ability to identify OLs at increased risk of cancer development is critical to improve control of oral carcinoma. Epithelial dysplasia is still the most important predictive factor in clinical practice, but recent studies have shown a substantial amount (3.9 to $11 \%$ ) of non-dysplastic OLs undergoing malignant transformation [18-20]. Histological assessment of dysplasia is in fact extremely subjective and significant interobserver and intraobserver variability in reading the degree of epithelial dysplasia is welldocumented [21]. Another factor is that histological diagnosis of an incisional biopsy is a "snapshot" of the lesion and sometimes underestimates the true nature of the whole lesion [19]. For these reasons, it is important to find alternative parameters allowing early detection of OLs without any dysplastic changes at risk of developing OSCC.

TP53 mutations are the commonest genetic damage found in human tumors and OSCC $[22,23]$ and are regarded as early events in carcinogenesis [24-26]. Overproduction of p53 inactive proteins is a well-documented consequence of TP53 genetic damage. Many studies on oral premalignant and malignant lesions have shown p53 overexpression ranging from $35 \%$ to $90 \%[13,15,27,28]$. Overexpression in OLs was further confirmed in recent studies [29-33]. In particular, De Oliveira et al. analyzed p53 protein expression in OSCC and premalignant lesions. They found a higher expression of p53 protein in OLs with respect to OSCC lesions (55.2 vs. 44.8\%) and emphasized the key role of p53 during early stages of carcinogenesis [29].

Visioli et al. analyzed p53 and p21 protein expression in non-dysplastic leukoplakias with different epithelial alterations (acanthosis, hyperkeratosis and acanthosis combined with hyperkeratosis), and in dysplastic leukoplakias. The results showed high p53 expression in both groups without any significant between groups difference [31]. They concluded that all OLs must be considered potentially malignant disorders irrespective of the presence or not of dysplasia, and patients should be kept under regular long-term clinical follow-up.

In the present longitudinal study, three out of seven OLs that evolved to OSCC showed high p53 values at the first examination, although 16 OLs with p53 overexpression did not progress to OSCC and four OLs with "normal" p53 expression did evolve to OSCC. These data do not allow p53 overexpression alone to be taken as a variable statistically associated with OSCC progression, at least in a small sample 


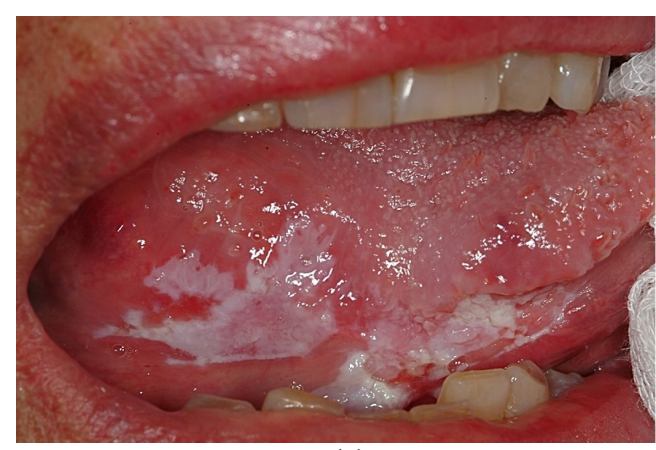

(a)

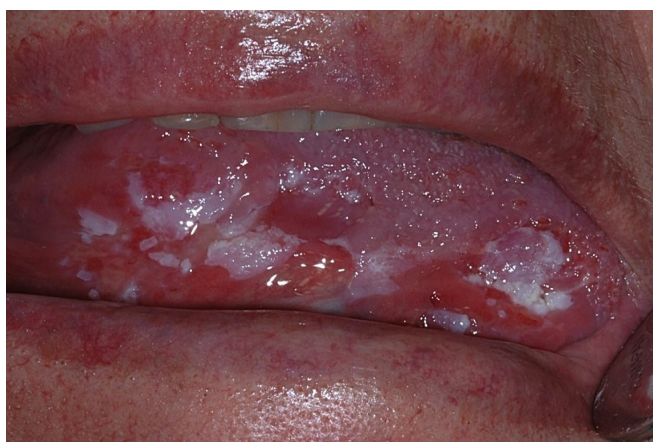

(b)

Fig. (3). A clinically and histologically non-homogeneous OL of the marginal tongue in a 77-year-old non-smoking female patient (a). A second incisional biopsy 36 months later disclosed OSCC (b).

Estimated Survival Function

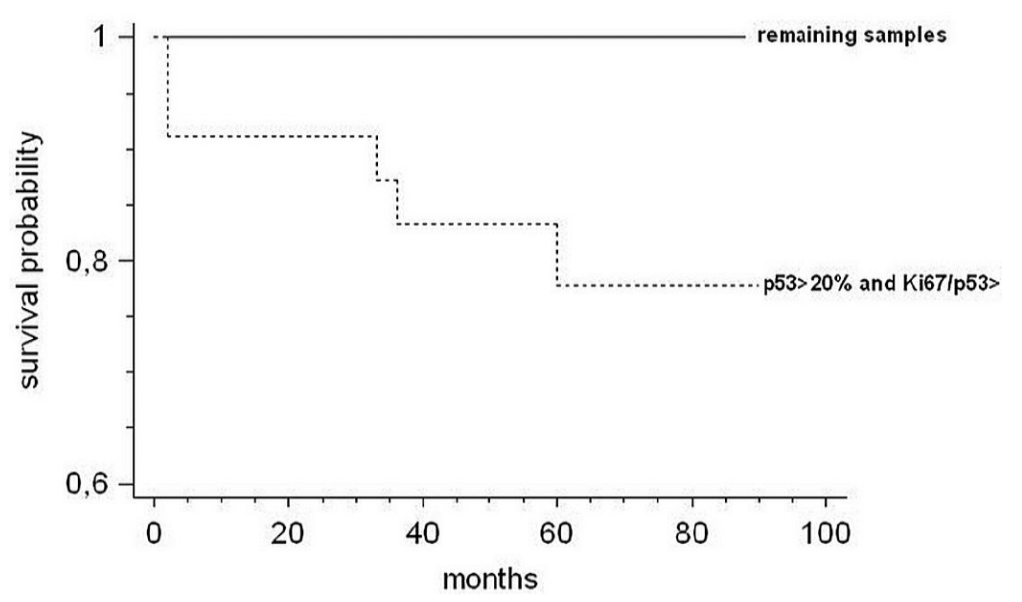

Fig. (4). The Cox proportional hazards method shows that p53 overexpression combined with a high Ki67/p53 ratio is the only variable significantly associated with OL that evolved into OSCC (Chi square 5.3; $<<0.02$ ).

population $[11,15,34]$. In fact, some mutations lead to errors in the p53 gene that result in the arrest or reduction of p53 protein synthesis and negative or reduced staining on immunohistochemistry. Tumors with nonsense or frameshift mutations also result in the production of unstable truncated proteins, which are also negative on immunohistochemistry $[35,36]$. Recently, Reddy et al. found weak p53 staining in nine out of 30 OLs with different grades of dysplasia [30].

In this connection, we previously assumed that the finding of "normal" or depressed p53 expression associated with an increased proliferation rate (increased mitotic/apoptosis ratio) might possibly identify genetically damaged lesions lacking a p53 protective role during cell cycling and at risk of progressing to p53 negative cancer [14]. The rationale was that an increased physiologic cell proliferation in nonneoplastic cells usually leads to overproduction of p53 protein as a guardian of epithelial growth $[14,37,38]$. Hence, a high proliferating rate associated with normal/reduced p53 expression may be interpreted as an impaired p53 production. The previous study used Ki67 protein as a marker of cell proliferation and a high $\mathrm{Ki67/p53}$ ratio as an index of impaired p53 response to a high cell turnover [14].

In the present cohort, four of the seven OLs that evolved to OSCC showed a high $\mathrm{Ki} 67 / \mathrm{p} 53$ ratio at the first examination, although 23 OLs without a high Ki67/p53 ratio did not progress to OSCC. Interestingly, the combination of $\mathrm{p} 53$ overexpression and high $\mathrm{Ki} 67 / \mathrm{p} 53$ ratio identified all seven OLs evolving to OSCC and was the only parameter statistically related to OSCC progression. However, overexpression of p53 and a high $\mathrm{Ki} 67 / \mathrm{p} 53$ ratio in the present cohort was only found in 46 out of 77 patients $(59.7 \%)$, and only seven of these $46(15 \%)$ OLs evolved to OSCC. Moreover, the avoidance of false negative results takes priority in the presence of a lesion predicted to develop cancer, and sensitivity is most important to maximize negative-predictive accuracy. It is noteworthy that none of the 31 OLs with normal p53 expression or a normal Ki67/p53 ratio evolved in OSCC during a mean follow-up period of 42 months (range 12-90).

In conclusion, our results suggest that OLs may be considered potentially malignant lesions even in the absence of histological dysplasia. Overexpression of p53 protein alone did not identify all OLs that subsequently developed to OSCC, whereas the combination of p53 and Ki67 expression did. The combined immunohistochemical expression of p53 and Ki67 proteins could represent a simple and inexpensive molecular marker for early detection of potentially malignant lesions at risk of developing OSCC. These data need to be confirmed in future studies with a longer follow-up involving a larger number of patients with non-dysplastic OLs. 


\section{CONFLICT OF INTEREST}

The authors declare no financial support or commercial association, current and within the past five years, that might pose a potential, perceived, or real conflict of interest.

\section{ACKNOWLEDGEMENTS}

Anne Collins edited the English text.

\section{REFERENCES}

[1] Ferlay J, Shin HR, Bray F, Forman D, Mathers C, Parkin DM. Estimates of worldwide burden of cancer in 2008: GLOBOCAN 2008. Int J Cancer 2010; 127: 2893-917.

[2] Silverman S, Jr., Gorsky M, Lozada F. Oral leukoplakia and malignant transformation. A follow-up study of 257 patients. Cancer 1984; 53: 563-8.

[3] Lumerman H, Freedman P, Kerpel S. Oral epithelial dysplasia and the development of invasive squamous cell carcinoma. Oral Surg Oral Med Oral Pathol Oral Radiol Endod 1995; 79: 321-9.

[4] Lee JJ, Hong WK, Hittelman WN, et al. Predicting cancer development in oral leukoplakia: ten years of translational research. Clin Cancer Res 2000; 6: 1702-10.

[5] van der Waal I. Potentially malignant disorders of the oral and oropharyngeal mucosa; terminology, classification and present concepts of management. Oral Oncol 2009; 45: 317-23.

[6] Hansen LS, Olson JA, Silverman S, Jr. Proliferative verrucous leukoplakia. A long-term study of thirty patients. Oral Surg Oral Med Oral Pathol 1985; 60: 285-98.

[7] Cabay RJ, Morton TH, Jr., Epstein JB. Proliferative verrucous leukoplakia and its progression to oral carcinoma: a review of the literature. J Oral Pathol Med 2007; 36: 255-61.

[8] van der Waal I, Reichart PA. Oral proliferative verrucous leukoplakia revisited. Oral Oncol 2008; 44: 719-816.

[9] Cruz I, Napier SS, van der Waal I, et al. Suprabasal p53 immunoexpression is strongly associated with high grade dysplasia and risk for malignant transformation in potentially malignant oral lesions from Northern Ireland. J Clin Pathol 2002; 55: 98-104.

[10] Califano J, Westra WH, Koch W, et al. Unknown primary head and neck squamous cell carcinoma: molecular identification of the site of origin. J Natl Cancer Inst 1999; 91: 599-604.

[11] Cruz IB, Snijders PJ, Meijer CJ, et al. p53 expression above the basal cell layer in oral mucosa is an early event of malignant transformation and has predictive value for developing oral squamous cell carcinoma. J Pathol 1998; 184: 360-8.

[12] Kovesi G, Szende B. Changes in apoptosis and mitotic index, p53 and Ki67 expression in various types of oral leukoplakia. Oncology 2003; 65: 331-6.

[13] Shin DM, Kim J, Ro JY, et al. Activation of p53 gene expression in premalignant lesions during head and neck tumorigenesis. Cancer Res 1994; 54: 321-6.

[14] Montebugnoli L, Felicetti L, Gissi DB, et al. Predictive Role of p53 Protein as a Single Marker or Associated to Ki67 Antigen in Oral Carcinogenesis. Open Dent J 2008; 2: 24-9.

[15] Warnakulasuriya S, Johnson NW, van der Waal I. Nomenclature and classification of potentially malignant disorders of the oral mucosa. J Oral Pathol Med 2007; 36: 575-80.

[16] El Naggar AK, Reichart PA. Proliferative verrucous leukoplakia and precancerous conditions. In: Barnes L, Eveson JW, Reichart P, Sidranski D, Eds. Pathology and genetics head and neck tumour. Lyon: World Health Classification of Tumours. IARC Press: Lyon, France 2005; p. 180.

[17] Gale N, Pilch BZ, Sidransky D, et al. Epithelia precursor lesions. In: Barnes L, Eveson JW, Reichart P, Sidranski D, Eds. Pathology and genetics Head and Neck tumours. Lyon: World Health Classification of Tumours 2005; p. 177.
[18] Holmstrup P, Vedtofte P, Reibel J, Stoltze K. Long-term treatment outcome of oral premalignant lesions. Oral Oncol 2006; 42: 46174.

[19] Holmstrup P, Vedtofte P, Reibel J, Stoltze K. Oral premalignant lesions: is a biopsy reliable? J Oral Pathol Med 2007; 36: 262-6.

[20] Saito T, Sugiura C, Hirai A, et al. Development of squamous cell carcinoma from pre-existent oral leukoplakia: with respect to treatment modality. Int J Oral Maxillofac Surg 2001; 30: 49-53.

[21] Abbey LM, Kaugars GE, Gunsolley JC, et al. Intra examiner and inter examiner reliability in the diagnosis of oral epithelial dysplasia. Oral Surg Oral Med Oral Pathol Oral Radiol Endod 1995; 80: 188-91.

[22] Greenblatt MS, Bennett WP, Hollstein M, Harris CC. Mutations in the p53 tumor suppressor gene: clues to cancer etiology and molecular pathogenesis. Cancer Res 1994; 54: 4855-78.

[23] Hollstein M, Sidransky D, Vogelstein B, Harris CC. p53 mutations in human cancers. Science 1991; 253: 49-53.

[24] Harris CC, Hollstein M. Clinical implications of the p53 tumorsuppressor gene. N Engl J Med 1993; 329: 1318-27.

[25] Levine AJ, Perry ME, Chang A, et al. The 1993 Walter Hubert Lecture: the role of the p53 tumour-suppressor gene in tumorigenesis. Br J Cancer 1994; 69: 409-16.

[26] Soussi T, Legros Y, Lubin R, Ori K, Schlichtolz B. Multifactorial analysis of $\mathrm{p} 53$ alteration in human cancer: a review. Int $\mathrm{J}$ Cancer 1994; 57: 1-9.

[27] Kaur J, Srivastava A, Ralhan R. Overexpression of p53 protein in betel- and tobacco-related human oral dysplasia and squamous-cell carcinoma in India. Int J Cancer 1994; 58: 340-5.

[28] Regezi JA, Zarbo RJ, Regev E, Pisanty S, Silverman S, Gazit D. p53 protein expression in sequential biopsies of oral dysplasias and in situ carcinomas. J Oral Pathol Med 1995; 24:18-22.

[29] de Oliveira MG, Ramalho LM, Gaiao L, Pozza DH, de Mello RA. Retinoblastoma and p53 protein expression in pre-malignant oral lesions and oral squamous cell carcinoma. Mol Med Rep 2012; 6: 163-6.

[30] Reddy VM, Kamath A, Radhakrishnan RA. p53 immunoprofiling of potentially malignant oral disorders: a case series analysis. Indian J Cancer 2012; 49: 27-32.

[31] Visioli F, Lauxen IS, Filho SM, Rados PV. Expression of the cell cycle regulation proteins $\mathrm{p} 53$ and $21 \mathrm{WAF} 1$ in different types of non-dysplastic leukoplakias. J Appl Oral Sci 2012; 20: 369-75.

[32] Nasser W, Flechtenmacher C, Holzinger D, Hofele C, Bosch FX. Aberrant expression of p53, p16INK4a and Ki-67 as basic biomarker for malignant progression of oral leukoplakias. J Oral Pathol Med 2011; 40: 629-35.

[33] Varun BR, Ranganathan K, Rao UK, Joshua E. Immunohistochemical detection of p53 and p63 in oral squamous cell carcinoma, oral leukoplakia, and oral submucous fibrosis. J Investig Clin Dent 2014; 5: 214-9.

[34] Ogden GR, Chisholm DM, Morris AM, Stevenson JH. Overexpression of p53 in normal oral mucosa of oral cancer patients does not necessarily predict further malignant disease. J Pathol 1997; 182:180-4.

[35] Chang F, Syrjanen S, Syrjanen K. Implications of the p53 tumorsuppressor gene in clinical oncology. J Clin Oncol 1995; 13: 100922.

[36] Fisher CJ, Gillett CE, Vojtesek B, Barnes DM, Millis RR. Problems with p53 immunohistochemical staining: the effect of fixation and variation in the methods of evaluation. Br J Cancer 1994; 69: 26-31.

[37] Hussein MR, El-Ghorori RM, El-Rahman Y. Alterations of p53, BCL-2, and hMSH2 protein expression in the normal brain tissues, gliosis, and gliomas. Int J Exp Pathol 2006; 87: 297-306.

[38] Soini Y, Kamel D, Paakko P, Leetho VP, Oikarinen A, Vahakangas KV. Aberrant accumulation of p53 associates with Ki67 and mitotic count in benign skin lesions. Br J Dermatol 1994; 131: 51420 .

Received: November 12, 2014

Revised: December 01, 2014

Accepted: December 17, 2014

(C) Gissi et al.; Licensee Bentham Open.

This is an open access article licensed under the terms of the Creative Commons Attribution Non-Commercial License (http://creativecommons.org/licenses/by-nc/3.0/) which permits unrestricted, non-commercial use, distribution and reproduction in any medium, provided the work is properly cited. 